\title{
Stress assignment in aphasia: Word and non-word reading and non-word repetition
}

\author{
Elise de Bree *, Esther Janse, Anne Marie van de Zande \\ Utrecht Institute of Linguistics OTS, Utrecht University, Trans 10, $3512 \mathrm{JK}$ Utrecht, The Netherlands
}

Accepted 3 July 2007

Available online 13 August 2007

\begin{abstract}
This paper investigates stress assignment in Dutch aphasic patients in non-word repetition, as well as in real-word and non-word reading. Performance on the non-word reading task was similar for the aphasic patients and the control group, as mainly regular stress was assigned to the targets. However, there were group differences on the real-word reading and non-word repetition tasks. Unlike the nonbrain-damaged group, the patients showed a strong regularization tendency in their repetition of irregular patterns. The patients' stress error patterns suggest an impairment in retention or retrieval of targets with irregular stress patterns. Limited verbal short-term memory is proposed as a possible underlying cause for the stress difficulties.
\end{abstract}

(C) 2007 Elsevier Inc. All rights reserved.

Keywords: Word stress; Stress errors; Aphasia; Lexical stress; Verbal short-term memory

\section{Introduction}

This paper investigates word stress production in Dutch patients with aphasia. Over the years, evidence has accumulated that patients with aphasia may display difficulties in stress assignment (Cappa, Nespor, Ielasi, \& Miozzo, 1997; Galante, Tralli, Zuffi, \& Avanzi, 2000; Janssen, 2003; Laganaro, Vacheresse, \& Frauenfelder, 2002; Miceli \& Caramazza, 1993). The general pattern of findings for the patients under investigation is that regularization of stress occurs in their output. In other words, their stress production tends towards the most frequent patterns in the language. Regular stress patterns in Italian and German are based on the syllable structure of the words. In Italian, for example, underived words with a heavy penultimate syllable (konténto [glad]) generally take penultimate stress. Italian patients with aphasia have been found to alter stress assignment of words with exceptional or irregu-

\footnotetext{
${ }^{*}$ Corresponding author. Fax: +31 302536000 .

E-mail address: elise.debree@let.uu.nl (E. de Bree).
}

lar stress (e.g. mándorla [almond]) to regular stress position (mandórla).

The stress difficulties have generally been attested in reading aloud words and non-words (Cappa et al., 1997; Galante et al., 2000; Janssen, 2003; Laganaro et al., 2002; Miceli \& Caramazza, 1993), but also in picture naming and spontaneous speech (Cappa et al., 1997; Laganaro et al., 2002). It has been proposed that the stress errors in reading aloud reflect reliance on a non-lexical route in reading. The patients no longer have fast access to the lexical representation of the words, and instead rely on grapheme-to-phoneme conversion and syllable structure to assign stress. Similarly, for stress regularization in naming or spontaneous speech, it seems that lexical stress-specific information is partly unavailable or inaccessible, forcing the patient to rely on syllable structure, or on the generation of a default metrical structure, see Butterworth (1992).

However, one area of stress realization that has not been assessed in-depth in patients before, is stress production in non-word repetition. Such an investigation allows an analysis of the productivity of stress rules. Subjects have to repeat non-words with stress patterns differing in degree 
of regularity. By using non-words, we are able to test repetition performance of the same segmental string and syllabic structure in several stress conditions. This is a more controlled way of investigating whether patients rely on syllabic structure in stress assignment than choosing real words of different metrical patterns.

Such an approach also allows us to assess whether the data can be accounted for by neural network models, such as connectionist models. These models have been proposed to account for (typical acquisition of) Dutch word stress (Daelemans, Gillis, \& Durieux, 1994; Gillis, Daelemans, \& Durieux, 2000; Joanisse \& Curtin, 1999). In a connectionist model, connections of input to output values each carry their own weight and activation threshold, based on probabilistic constraints. These connections determine patterns of activation in a network (Seidenberg, 1997). Strong connections are associated with patterns that occur often, i.e. regular stress patterns. As a consequence, frequent patterns will be produced faster than low frequent patterns with weak connections, or less frequent patterns are regularized in the output. Connectionist models are ideally suited for accommodating quasiregular behaviour as in Dutch word stress (see Section 2), which includes regular and (highly) irregular stress patterns.

Connectionist models have also been for reading (e.g. Plaut, McClelland, Seidenberg, \& Patterson, 1996). The process of reading involves three connectionist networks, one that maps orthography to phonology, one that maps orthography to semantics, and one that maps semantics to phonology. When only the orthography to phonology route is available, low-frequency words are not recognized and are regularized. In cases of stress assignment, this will render regularization of stress during reading.

Network approaches have also been proposed to account for data of aphasic patients (e.g. Gupta \& MacWhinney, 1997) and have been applied for modelling data of aphasic patients. Dell, Schwartz, Martin, Saffran, and Gagnon (1997), for example, modelled picture-naming errors of aphasic and non-aphasic speakers through a spreading-activation model. They first modelled normal error patterns in the mapping between the conceptual representation and the phonological form. Brain damage may reduce the integrity of representations at each level in the network and may reduce transmission of activation between levels. Lesioning the model can be accomplished by altering activation decay rate and/or connection weight.

The relation between verbal short-term memory and long-term phonological knowledge has been accounted for in (amongst others) Gathercole and Martin (1996), who stressed the impact of long-term phonological knowledge on immediate recall or non-word repetition. Gupta and MacWhinney (1997) also showed that non-word repetition and serial recall depend crucially on the strength of long-term phonological knowledge in the lexical system. This means that, for example, non-words with high neigh- bourhood density and phonotactic probability are recalled more easily than those with lower neighbourhood density.

In connectionist terms then, low frequent patterns with weak connections are difficult to access in reading and are difficult to retain in nonword repetition. Particularly if the network has been lesioned, activation of the target pattern will often remain below threshold. Thus, by analogy, a tendency of stress regularization can be anticipated to occur. Patients do not have fast access to the lexical representations of words and have difficulty retaining non-word targets. Instead, they rely on grapheme-to-phoneme conversion and syllable structure to assign stress.

The present study aims to investigate stress assignment in Dutch patients with aphasia through repetition of non-words, as well as through reading aloud words and non-words. We appreciate, however, that not all patients may be able to perform all tasks. By tapping both reading and speech domains, we hope to gain a more complete picture of patients' stress abilities. Similar to a study by Nickels and Howard (1999), we anticipate that the reading task will be more problematic for the patients than a repetition task. The repetition task results will therefore be the focus of the study. We specifically aim to test the following hypotheses:

- The findings on the word reading task will replicate previous findings of German and Italian patients with aphasia. In other words, Dutch patients with aphasia will resort to stress changes in the word reading task. These changes will lead to more regular stress realizations (cf. Section 2 on Dutch word stress). The non-brain-damaged participants will not show regularization.

- In the non-word reading task, both the aphasic patient group and the controls will mainly assign regular stress to the non-words.

- The aphasic patients will have more difficulty with stress production in repetition of non-words with irregular stress patterns than a non-brain-damaged control group. The aphasic population's non-word repetition is expected to show a greater tendency towards regularization of irregular stress patterns than is expected for the control group.

This paper thus not only attempts to replicate findings of stress production of aphasic patients in Dutch, but also includes systematic analyses of word and non-word reading, as well as non-word repetition. Furthermore, we will look beyond the production of stress 'errors', but will also focus on the types of errors the patients make. We have included data of six patients, instead of only those of one or two patients, as previous research has done. This study also includes an age-matched control group, absent in (most of) the previous studies. Additionally, it will be assessed whether the findings of the aphasic participants can be accounted for by a connectionist network. Before 
the study can be reported, however, it is time to turn to Dutch word stress assignment.

\section{Dutch word stress}

Phonetically, stressed syllables in Dutch show longer duration and greater perceived loudness than unstressed syllables (Sluijter, 1995). Unstressed vowels are candidates for reduction (Kager, 1989; Trommelen \& Zonneveld, 1999), although reduction is much less pervasive than in English. Typologically, Dutch is a language with lexical word stress, i.e. regularities take the form of strong tendencies but do have exceptions. The basic stress system for monomorphemic words (i.e., words lacking morphological structure), which we focus on here, is trochaic, favouring patterns of strong-weak syllables (e.g. $f o_{\mathrm{s}} t o_{\mathrm{w}}$ [photo]).

A major characteristic of Dutch monomorphemic word stress is the three syllable window generalization (Kager, 1989; Trommelen \& Zonneveld, 1989, 1999), which holds that main stress never falls on the pre-antepenultimate syllable or prior ( ${ }^{*}$ mácaroni [macaroni]), but always on one of the last three syllables. The Dutch word stress system is quantity-sensitive: syllable weight, based on the structure of the rhyme (the syllable nucleus and coda), co-determines the position of stress. Taking into account the weight of the final (and prefinal) syllable, the following rules apply to main stress in monomorphemic words (Daelemans et al., 1994; Kager, 1989; Nouveau, 1994; Trommelen, 1991):

- If the final syllable is light (ends in a long vowel) main word stress is prefinal, regardless of the structure of the prefinal syllable, e.g. py.já.ma [pyjamas], a.gén.da [diary] (In terms of spelling, vowels in open syllables are long; in closed syllables, doubly-spelled vowels are long, singly-spelled vowels are short).

- If the final syllable is heavy (ends in a vowel and single consonant) main word stress is prefinal or antepenultimate, depending on the nature of the prefinal syllable; if the prefinal syllable is heavy, stress is prefinal, e.g. e.lék.tron [electron], ro.don.dén.dron [rhododendron], if the prefinal syllable is light, stress is assigned on the antepenultimate syllable, e.g. á.na.nas [pineapple], Je.rú.za.lem [Jerusalem].

- If the final syllable is superheavy (ends in a vowel and two consonants or ends in a long vowel and a single consonant) main word stress is final, e.g. stu.dént [student], te.le.fóon [telephone], pre.si.dént [president].

- Final diphthongs (vowel sequences of two different vowels) behave like superheavies; kar.wéi [chore], a.ve.ríj [damage].

These regularities are presented visually in Appendix A. Thus, Dutch regular stress patterns include stress on different positions of the word (prefinal in pyjáma [pyjamas], antepenultimate in ánanas [pineapple], final in telefóon [telephone]). In order to correctly assign stress, knowledge of the role of syllable weight (that is, the exact segmental composition of the syllable nucleus and coda) has to be available.

Besides these main stress rules, irregular stress patterns also occur in Dutch. The irregular patterns, which are phonologically more marked and lower in frequency, are further divided into irregular and highly irregular patterns (Kager, 1989; Nouveau, 1994; Trommelen, 1991; Trommelen \& Zonneveld, 1989). For final light syllables, for example, an irregular pattern would be Éskimo [Eskimo] and a highly irregular pattern would be paraplú [umbrella].

Whereas regular stress patterns are deduced on the basis of syllable weight (determined by syllable structure), the (highly) irregular stress patterns are less evident. If Dutch patients with aphasia behave similarly to the Italian and German patients mentioned before, the production of regular stress patterns in the non-word repetition task should be easier than that of (highly) irregular stress patterns. Furthermore, stress patterns of words of the irregular types will be produced as regular patterns.

In sum, this study aims to examine word stress production in reading aloud words and non-words and in nonword repetition in Dutch aphasic patients. The goal is to assess whether the aphasic patient group has particular difficulties with irregular stress patterns, compared to a nonbrain-damaged control group. The expectation is that if the target items are produced non-identically, the aphasic patients will show a strong tendency towards regularization of the stress patterns.

\section{Methods}

\subsection{Participants}

Subjects tested were six aphasic patients ( 3 male and 3 female participants, mean age 54.3 years, SD 6.1 years) and six age-matched (mean age 54.3 years, SD 4.5 years) control subjects (also three male and three female). All participants were monolingual and native speakers of Dutch. The patient group participants were recruited in an activity centre for people with aphasia. They gave their informed consent to participate in the study. Patients were all at least 2 years post-onset. Because the previous diagnosis might no longer be valid, the aphasic participants were administered with the diagnostic aphasia test used in the Netherlands (the Dutch version of the Aachen Aphasia Test (AAT); Graetz, de Bleser, \& Willmes, 1992). The diagnostic test was administered to each patient by a Dutch speech therapist (third author). The spontaneous language data were recorded with a Sony MD-LP mini-disc of type MZ-R700. Patient information, including their classification according to the Aachen Aphasia Test and the scores on the AAT subparts, is given in Table 1. All participants declared to have intact hearing. The patients all became aphasic after a CVA in the left hemisphere.

All the aphasic participants had relatively poor syntax (short incomplete sentences in which verb inflection and function words were often missing) and moderately 
Table 1

Patient information

\begin{tabular}{|c|c|c|c|c|c|c|}
\hline Aphasic patient & 1 & 2 & 3 & 4 & 5 & 6 \\
\hline Age & 47 & 58 & 62 & 51 & 59 & 49 \\
\hline Gender & Male & Female & Male & Female & Female & Male \\
\hline Post-onset & 5.9 & 6.7 & 5.0 & 7.8 & 6.1 & 2.6 \\
\hline Syndrome diagnosis & $\begin{array}{l}\text { Not } \\
\text { classifiable }\end{array}$ & $\begin{array}{l}\text { Not } \\
\text { classifiable }\end{array}$ & $\begin{array}{l}\text { Not } \\
\text { classifiable }\end{array}$ & Broca's & Amnestic & $\begin{array}{l}\text { Not } \\
\text { classifiable }\end{array}$ \\
\hline \multicolumn{7}{|l|}{ Aachen aphasia test scores } \\
\hline \multicolumn{7}{|l|}{ Spontaneous language scores (all subscores $\max =5$ ) } \\
\hline Communicative behaviour & 3 & 3 & 3 & 2 & 4 & 3 \\
\hline Articulation and prosody & 4 & 4 & 4 & 4 & 5 & 4 \\
\hline Formulaic language & 4 & 4 & 5 & 4 & 5 & 5 \\
\hline Semantics & 3 & 3 & 4 & 3 & 4 & 5 \\
\hline Phonology & 3 & 3 & 3 & 3 & 4 & 4 \\
\hline Syntax & 2 & 2 & 2 & 1 & 2 & 2 \\
\hline \multicolumn{7}{|l|}{ Scores on other AAT components ${ }^{\mathrm{a}}$} \\
\hline Token test $^{\mathrm{b}}(\max =0)$ & $30(5, \mathrm{~A})$ & $37(4, \mathrm{~A})$ & $25(5, \mathrm{~A})$ & $29(5, \mathrm{~A})$ & $10(7, \mathrm{~L})$ & $13(6, \mathrm{~L})$ \\
\hline Repetition $(\max =150)$ & $134(7, \mathrm{~L})$ & $103(5, \mathrm{~A})$ & $127(6, \mathrm{~L})$ & $101(5, \mathrm{~A})$ & $125(6, \mathrm{~L})$ & $143(8, M)$ \\
\hline Written language $(\max =3 * 30=90)$ & $62(5, A)$ & $23(3, \mathrm{H})$ & $55(5, \mathrm{~A})$ & $68(6, \mathrm{~L})$ & $76(6, \mathrm{~L})$ & $84(7, \mathrm{~L})$ \\
\hline Reading aloud words/short sentences & 25 & 14 & 23 & 25 & 23 & 26 \\
\hline Combining letter blocks (dictation) & 23 & 6 & 22 & 23 & 27 & 29 \\
\hline Writing (dictation) & 14 & 3 & 10 & 20 & 26 & 29 \\
\hline $\begin{array}{l}\text { Naming (describing pictures, colors or situations; } \\
\max =120)\end{array}$ & $40(3, \mathrm{H})$ & $79(5, \mathrm{~A})$ & $97(6, \mathrm{~L})$ & $90(6, \mathrm{~L})$ & $100(7, \mathrm{~L})$ & $97(6, \mathrm{~L})$ \\
\hline Comprehension $(\max =2 * 60=120)$ & $99(7, \mathrm{~L})$ & $89(5, \mathrm{~A})$ & $87(5, \mathrm{~A})$ & $92(6, \mathrm{~L})$ & $90(6, \mathrm{~L})$ & $91(6, L)$ \\
\hline Matching auditory word/sentence to picture & 57 & 45 & 48 & 47 & 46 & 40 \\
\hline Matching written word/sentence to picture & 42 & 44 & 39 & 45 & 44 & 51 \\
\hline
\end{tabular}

${ }^{\mathrm{a}}$ The raw scores on the AAT subtests are given, plus the transformed scores in brackets: the stanine scores (ranging from $1=$ very poor to $9=$ very superior) and the accompanying severity label (Heavy, Average, Light, Minimal).

${ }^{\mathrm{b}}$ Only on this subtest, scores indicate number of errors; maximum (best possible) score is therefore 0 (range 0-50).

impaired phonology (small/moderate number of phonemic paraphasias). The patients showed no signs of verbal or oral apraxia or dysarthria. In terms of semantics, their spontaneous language showed some semantic paraphasias and (a varying degree of) word finding problems. There were differences within the group with respect to reading and naming performance. None of the patients had severe auditory comprehension problems. We will return to the issue of generalizability of results of this specific aphasic patient group in Section 5.

\subsection{Materials}

The patients were presented with three experimental tasks; a real-word reading task, a non-word reading task, and a non-word repetition task. In the first (real-word reading) task, participants were asked to read aloud 34 Dutch monomorphemic words varying in word length (two to four syllables), final syllable weight (light, heavy, superheavy, and diphthong), and stress regularity (regular, irregular, and highly irregular). For example, a three-syllable word with a final light syllable with regular (pyjama [pyjamas]), irregular (Éskimo, [Eskimo]), and highly irregular stress (paraplú [umbrella]), were included. Stimuli of the real-word reading task are presented in Appendix B.

The second task, the non-word reading task, was based on a study by Nouveau (1994). It contained 14 phonotactically legal non-words, varying in length (two to four syllables), and final syllable weight (light, heavy, superheavy, and diphthong). The words had to resemble monomorphemic Dutch words, without being too similar to existing words. No stress pattern is 'correct' for these targets, as they are non-words. Thus, the three-syllable non-word with a final light syllable fenimo could be read as fenimo, yielding a regular stress pattern, similar to the real word pyjáma (see Appendix A). However, it could also be read as fénimo (irregular stress, similar to Éskimo), or fenimó (highly irregular stress, similar to paraplú). Stimuli of the non-word reading task are presented in Appendix B.

Finally, the non-word repetition task was also based on Nouveau's work (1994). She created non-words for each stress category of Dutch (as indicated above). Thus, a non-word could occur with regular (karabilo), irregular (karábilo), and highly irregular (karabiló) stress. Furthermore, she included an additional category of words with prohibited stress ( ${ }^{*}$ kárabilo). These prohibited targets either violate the three syllable window constraint (*kárabilo) or the mandatory effect of syllable weight $\left({ }^{*} k a\right.$ anakta). Subjects were asked to repeat these non-words, and their realizations were assumed to reflect their word stress competence.

The tasks' foundation were the 14 phonotactically legal non-words varying in length (two to four syllables), 
Table 2

Examples of non-word repetition coding

\begin{tabular}{lllll}
\hline Non-word: katipón & Transcription: kati'pon & & & Regularity target: irregular \\
\hline Realization & Transcription & Identical? & Change & Regularity realization \\
katipón & kati'pon & Identical & - & Irregular \\
patipón & pati'pon & Identical & - & Irregular \\
kokatipón & kokati'pon & Equivalent & Syllable addition & Irregular \\
kapón & ka'pon & Equivalent & Syllable omission & Irregular \\
kátipon & kati'pon & More regular & Stress shift & Regular \\
katipónt & kati'pont & More regular & Weight gain & Regular \\
katipo & kati'po & Less regular & Weight loss & Highly irregular \\
katípon & ka'tipon & Less regular & Stress shift & Highly irregular \\
katíkpo & katik'po & Less regular & Weight gain weight loss & Highly irregular \\
kápon & kapon & More regular & Syllable omission stress shift & Regular \\
\hline
\end{tabular}

Participants' realizations are coded for changes in regularity, errors, and degree of regularity. The stimulus /kati'pon/ is taken as an example to illustrate the data encoding.

and final syllable weight (light, heavy, superheavy, and diphthong) as those of the non-word reading task. Shifting primary stress (e.g. bóla vs bolá) to every other syllable in those 14 non-words yielded 39 stimuli, belonging to different categories of regularity, with regular, irregular, highly irregular, and prohibited stress.

In the present study, Nouveau's original stimuli were slightly altered in order to (1) minimize occurrence of non-words and syllables that closely resemble existing words, and (2) to avoid repeated occurrence of similarly sounding targets. Thus, instead of presenting talaktan three times as taláktan (regular type), talaktán (irregular type) and tálaktan (prohibited type), participants heard taláktan, kawaptán, and pánaktam. The danger of inducing differences due to segmental changes is appreciated, but the conflicting desire to prevent data loss as much as possible prevailed.

The stimuli were recorded by a female speaker of Dutch (first author) to ensure consistent rate, accuracy, and intonation of presentation. In order to assess whether word stress of these recordings was unambiguous, five naïve adult listeners were asked to judge the recordings of the 39 non-words. Their perceived stress assignment fully agreed with those of the design $(100 \%)$. The non-word repetition stimuli are presented in Appendix C.

\subsection{Procedure and data analysis}

The patients were tested at the rehabilitation centre in a quiet room. The Aachen Aphasia Test was presented in a session prior to the experimental tasks. The control participants were tested at their homes.

In the real-word reading task, each word was presented to the participants on a sheet of paper in a large font. Their realizations were recorded on minidisc. The same procedure was followed in the non-word reading task.

In the non-word repetition task, participants were instructed to repeat the word immediately after they heard it. The non-words were played to them on a Sony CD- player with two loudspeakers to provide a clear stereo sound.

Recordings of participants' data were converted to sound files and a broad transcription was made independently by the first and third author. Between-transcriber agreement on transcription of syllable structure and word length was 97\% (1013/1044) and 97\% (1015/1044) for stress. When no consensus between these transcribers was reached (7/60 realizations), soundfiles were presented to another transcriber (second author).

Supra-segmental analyses were made of the realizations produced by the aphasic patients and the non-brain-damaged control participants. Their realizations were coded for number of syllables, final syllable weight, stress placement, and stress regularity class. Furthermore, it was scored whether the participants' realizations were 'identical' or 'non-identical'. For the word reading task and the non-word repetition task, 'identical' refers to realizations identical in word shape (syllable structure and word length) and word stress. Realizations with identical word shape and word stress as the target, but incorrect phonemes (e.g. patipón for katipón) were also scored as identical, as stress assignment of these realizations was similar to the target. Non-identical realizations were scored as 'equivalent' if the regularity of the participant's rendition matched that of the target, as 'more regular' when it was a more regular realization (e.g. from (highly) irregular to regular), and 'less regular' when it was a less regular realization (e.g. from regular to (highly) irregular). The types of changes participants applied were also tallied. Examples of coding and scoring are presented in Table 2.

\section{Results}

\subsection{Reading results real words}

The hypothesis tested for the real-word data is that the number of identical realizations of aphasic patients will be lower than those of the control participants, mainly for words with (highly) irregular stress. Words with (highly) irregular stress patterns are expected to be altered to yield 
more regular stress patterns. Counts and proportions of identical and non-identical realizations are provided in Table 3. It should be borne in mind that participants were presented with 14 regular items, 12 irregular items, and eight highly irregular items. Given that there are 6 participants in each group, the total number of observations $(N)$ is 84 for the regular stress cell, 72 in the irregular, and 48 in the highly irregular cell of Table 3 .

For all participants, the proportion of identical realizations (arcsine transformed) for all three stress regularity types was entered into an ANOVA by subjects (nested under participant group) to test the effects of Group (between subjects) and Regularity Type (within subjects). The results showed significant main effects of Group $\left(F_{1}(1,10)=19.88, \quad p=.001\right)$ and of Regularity Type $\left(F_{1}(2,9)=24.30, p<.001\right)$. Thus, whereas the aphasic participants displayed fewer identical realizations overall, both groups showed decreasing performance going from regular to highly irregular types. The interaction between Group and Regularity did not reach significance $\left(F_{1}(2,9)=1.56\right.$, n.s.).

With respect to the non-identical responses, the table shows that, apart from the zero responses in which production was obviously too difficult, most of the changes, for both participant groups, resulted in 'equivalent' or 'more regular' realizations. Thus, the participants either attempted to adhere to the regularity of the stress pattern of the word (appéndix [appendix] $\rightarrow$ péndix, marionét [puppet] $\rightarrow$ maritón), or they altered it into a more regular stress pattern (e.g. Krákatau [Krakatau] $\rightarrow$ Krakatáu, óóievaar [stork] $\rightarrow$ ooieváár). The aphasic participants resorted to these strategies more often than the control group. Errors in the experimental word reading task thus mainly occurred in irregular targets (e.g. robot, eiland, and krokodil) and in (irregular) targets with a low frequency of occurrence (e.g. bombardon, Prometheus, and marionet). These findings then confirm those of previous studies of stress assignment in real-word reading by aphasic participants. They also agree with predictions derived from a connectionist model.

As different reading scores were found for the aphasic participant group (Table 1), it was of interest to establish whether a relationship between the score on the AAT
Reading aloud task and the identical score on this experimental word reading task was attested. A strong correlation was found when entering the data of all 6 aphasic participants (Pearson's correlation, $R=0.85$ ). The heterogeneity of performance attested in the AAT reading aloud scores is thus also visible in the real-word reading task. However, when the data of patient 2, the patient whose score on the AAT reading aloud task was only 14 (out of 30 ) and on the experimental word stress reading task was only 16 (out of 34) were excluded, there was no correlation $(R=-0.08)$. The results of the other speakers were all higher and more similar to each other. The lack of a significant correlation (after exclusion of patient 2) between the AAT reading scores and the present reading results may be due to this reduced variance in the patients' data.

\subsection{Reading results non-words}

The expectation for the reading task is that both aphasic patients and control participants will adhere to the stress assignment rules of Dutch in reading out non-words. In other words, it is anticipated that the non-words will be assigned regular stress.

One patient (patient 2) did not produce any realizations at all (this patient had also shown considerably poorer reading performance than the other patients in the Aachen Aphasia Test; cf. Table 1). Thus, the data of the remaining five patients are presented. However, there were two instances where a zero realization was made and five lexicalizations (non-word turned into a real word). These will be excluded from the analyses. In sum, patients produced only 63 valid realizations out of a maximum of 70 ( 5 participants $* 14$ non-words). Some words were uttered a number of times by the same participant to improve the reading. In those cases, the response that corresponded best to the target structure was selected.

Before the question can be answered whether aphasic patients adhere to the stress rules of Dutch in their stress assignment, the correspondence in word length (in terms of syllable number) between the target items and the observed realizations is investigated. If the longer words are problematic, this interferes with our specifically designed materials. Table 4 presents the observed word

Table 3

Results of the real-word reading task

\begin{tabular}{|c|c|c|c|c|c|c|c|}
\hline \multirow[t]{2}{*}{ Participants } & \multirow[t]{2}{*}{ Regularity of stress pattern } & \multirow[t]{2}{*}{ Identical realizations } & \multicolumn{5}{|c|}{ Non-identical realizations } \\
\hline & & & Zero & Other word & Equival & More regular & Less regular \\
\hline \multirow[t]{3}{*}{ Aphasic participants } & Regular $(N=84)$ & $73(87 \%)$ & 4 & 0 & 6 & 0 & 1 \\
\hline & $\operatorname{Irregular}(N=72)$ & $52(72 \%)$ & 6 & 5 & 5 & 3 & 1 \\
\hline & Highly irregular $(N=48)$ & $24(50 \%)$ & 8 & 2 & 6 & 8 & 0 \\
\hline \multirow[t]{3}{*}{ Control participants } & Regular $(N=84)$ & $84(100 \%)$ & 0 & 0 & 0 & 0 & 0 \\
\hline & Irregular $(N=72)$ & $70(97 \%)$ & 0 & 0 & 0 & 2 & 0 \\
\hline & Highly irregular $(N=48)$ & $41(85 \%)$ & 0 & 0 & 0 & 7 & 0 \\
\hline
\end{tabular}

Identical, realization of target structure and stress pattern; Zero, no response; Other word, substitution to another word; Equival, realization of target with errors, but with same regularity, More regular, realization of target altered to a more regular category; Less regular, realization of target to a less regular category. 
Table 4

Observations concerning word length output (non-word reading)

\begin{tabular}{llllrl}
\hline & \multicolumn{5}{l}{ Syllable number in realizations } \\
\cline { 2 - 6 } & Zero & \multicolumn{1}{l}{1} & \multicolumn{1}{c}{2} & 3 & 4 \\
\hline 2-Syllable targets $(N=5 * 5=25)$ & 0 & 0 & 23 & 2 & 0 \\
3-Syllable targets $(N=5 * 7=35)$ & 2 & 0 & 4 & 23 & 6 \\
4-Syllable targets $(N=5 * 2=10)$ & 0 & 0 & 0 & 5 & 5 \\
\hline
\end{tabular}

Zero, no response.

length in the realizations of the aphasic group ( 5 patients), divided by word length of the target non-words. The results of the control group are not displayed because the number of syllables in their productions always matched the number of target syllables.

As is clear from the limited number of realizations, and from Table 4, reading out (longer) non-words appeared to be extremely problematic for the aphasic patients. This difficulty related to reading non-words could be due to a form of dyslexia that may occur in patients with aphasia; phonological dyslexia (Galante et al., 2000; Southwood \& Chatterjee, 2001), which involves a specific impairment of the non-lexical reading route.

Given the limited number of realizations in which the target word length was adhered to, the only remaining analysis is on the stress regularity pattern of the realized non-words. Table 5 below provides the distribution of the realizations over the markedness categories for both groups of participants.

The distribution of both groups seems the same in that regular stress (e.g. kanakta $\rightarrow$ kanákta) was assigned most often and prohibited stress (e.g. kanakta $\rightarrow$ kánakta) was never produced. A chi-squared analysis confirms that the distribution of stress assignment is the same for both groups $\left(\chi^{2}(2)=4.59, p>.1\right)$. Even though there were no differences between the groups, the aphasic participants still displayed a few highly irregular realizations. We defer discussion of this phenomenon until discussion of the nonword repetition results.

Summing up, in both the real and non-word reading test, the two groups of participants showed a similar partitioning of stress regularity preferences: regular $>$ irregular $>$ highly irregular stress, in line with the expectations. Furthermore, the number of identical responses of the real-word reading task was lower for the aphasic subjects due to higher rates of regularization.

Table 5

Distribution of realizations divided by regularity of stress patterns for both groups of participants (non-word reading)

\begin{tabular}{lllll}
\hline & \multicolumn{2}{l}{ Regularity of stress pattern } & \\
\cline { 2 - 5 } & Regular & Irregular & $\begin{array}{l}\text { Highly } \\
\text { irregular }\end{array}$ & Prohibited \\
\hline $\begin{array}{c}\text { Aphasic participants (out } \\
\text { of } 63 \text { observations) }\end{array}$ & $34(54 \%)$ & $23(36 \%)$ & $7(11 \%)$ & 0 \\
$\begin{array}{c}\text { Control participants (out } \\
\text { of } 84 \text { observations) }\end{array}$ & $57(68 \%)$ & $24(28 \%)$ & $3(4 \%)$ & 0 \\
\hline
\end{tabular}

In the next section, stress assignment in a repetition task is investigated. Even though the real-word reading results provided evidence that aphasic patients had less trouble with regular stress patterns than with irregular metrical patterns, similar evidence from a task in which the metrical pattern is manipulated whilst maintaining segmentally identical words would provide a stronger case for their regularization tendency.

\subsection{Repetition of non-words}

This study aims to assess whether the aphasic patient group has particular difficulties with repetition of irregular stress patterns in non-words, compared to a non-braindamaged control group. The expectation is that if the target items are produced non-identically, the patients will show a strong tendency towards regularization of the stress patterns. The realizations of the patients and their controls were coded for word length in number of syllables, stress regularity, weight of the final syllable and stress placement (see Section 3). There was one aphasic patient (patient 2) who produced 11 zero responses, particularly for the targets of three and four syllables. This same patient had been unable to complete the non-word reading task.

Similar to the non-word reading section, the correspondence in word length between the target items and the observed realizations is addressed before we turn to stress assignment. Table 6 only shows the word length results for the aphasic patients, since word length realization always matched the target for the control participants.

These data show that word length did not cause major difficulties in the repetition task for most of the aphasic patients.

In order to investigate whether aphasic patients had more trouble correctly reproducing the targets with regular stress patterns than those with (highly) irregular and prohibited stress patterns, the counts and proportions of Identical realizations for targets of different regularity are shown in Table 7.

For all 12 participants, proportions (arcsine transformed) of identical realizations for all four stress regularity types was entered into an ANOVA by subjects to test the effects of Group (between subjects) and Regularity Type (within subjects). The results showed significant main effects of Group $\left(F_{1}(1,10)=32.00, p<.001\right)$ and of Regularity Type $\left(F_{1}(3,8)=14.85, p=.001\right)$. Most importantly,

Table 6

Word length realizations in the aphasic patient group (non-word repetition)

\begin{tabular}{ll}
\hline & Identical word length realizations out of $N=39$ \\
\hline Patient 1 & 39 \\
Patient 2 & 16 \\
Patient 3 & 38 \\
Patient 4 & 34 \\
Patient 5 & 39 \\
Patient 6 & 39 \\
\hline
\end{tabular}


Table 7

Results of the non-word repetition task (valid responses only)

\begin{tabular}{|c|c|c|c|c|c|}
\hline \multirow[t]{2}{*}{ Participants } & \multirow[t]{2}{*}{ Regularity of stress pattern } & \multicolumn{4}{|c|}{ Realization counts } \\
\hline & & Identical & Equivalent & More regular & Less regular \\
\hline Aphasic participants & $\begin{array}{l}\text { Regular }(N \max =14 * 6=84) \\
\text { Irregular }(N \max =12 * 6=72) \\
\text { Highly irregular }(N \max =9 * 6=54) \\
\text { Prohibited }(N \max =4 * 6=24)\end{array}$ & $\begin{array}{r}66(79 \%) \\
39(54 \%) \\
26(48 \%) \\
3(13 \%)\end{array}$ & $\begin{array}{r}7 \\
9 \\
11 \\
0\end{array}$ & $\begin{array}{r}0 \\
16 \\
13 \\
19\end{array}$ & $\begin{array}{l}6 \\
2 \\
1 \\
0\end{array}$ \\
\hline Control participants & $\begin{array}{l}\text { Regular }(N \max =14 * 6=84) \\
\text { Irregular }(N \max =12 * 6=72) \\
\text { Highly irregular }(N \max =9 * 6=54) \\
\text { Prohibited }(N \max =4 * 6=24)\end{array}$ & $\begin{array}{l}82(98 \%) \\
64(89 \%) \\
49(91 \%) \\
22(92 \%)\end{array}$ & $\begin{array}{l}0 \\
2 \\
0 \\
0\end{array}$ & $\begin{array}{l}0 \\
6 \\
5 \\
2\end{array}$ & $\begin{array}{l}2 \\
0 \\
0 \\
0\end{array}$ \\
\hline
\end{tabular}

Identical, realization of target structure and stress pattern; Equivalent, realization of target with errors, but with same regularity, More regular, realization of target altered to a more regular category; Less regular, realization of target to a less regular category.

the interaction between these two factors was also significant $\left(F_{1}(3,8)=5.51, p=.024\right)$. This confirms the hypothesis that the aphasic patients are differentially affected by the more irregular stress conditions.

The secondary question is whether the non-identical realizations are more regular than the input form. Table 7 clearly shows that most of the changes led to 'more regular' stress patterns, for both groups of participants. For the aphasic participants, collapsed over the realized materials, 27 observations of 'equivalent' changes were found, 48 'more regular' changes and only nine 'less regular' changes. In all instances, excepting one, weight loss, such as coda omission (/kariômon/ produced as /kariơ mo/) occurred, whereas the stress location of primary stress was maintained. Similarly, the few instances of irregularization in the non-word reading task also showed weight loss (bokaat was reduced to $/ \mathrm{bos}^{\mathrm{k} a} /$ ). In both tasks, speech production abilities, more specifically phonological problems, infrequently interfered with the stress assignment task. Thus, generally, the hypothesis of aphasics' regularization preference is confirmed. The few counterexamples can be accounted for in terms of reduction of phonological complexity. These phonological simplifications by the aphasic patients are in line with those previously reported (Den Ouden, 2002; Nickels \& Howard, 1999; Romani \& Galuzzi, 2005).

Table 8 presents the types and number of changes that occurred in the non-identical realizations of the participants. Note that multiple processes can occur in one word, e.g. / katiơppen/ being changed into /8̂tiơppon/ through syllable omission and stress shift.

Table 8

Change processes in the realizations of the participants (number of occurrences) (non-word repetition)

\begin{tabular}{llllll}
\hline Group & $\begin{array}{l}\text { Syllable } \\
\text { omission }\end{array}$ & $\begin{array}{l}\text { Syllable } \\
\text { addition }\end{array}$ & $\begin{array}{l}\text { Weight } \\
\text { loss }\end{array}$ & $\begin{array}{l}\text { Weight } \\
\text { gain }\end{array}$ & $\begin{array}{l}\text { Stress } \\
\text { shift }\end{array}$ \\
\hline Aphasic participants & $15(11)$ & $4(2)$ & $43(37)$ & $23(18)$ & $\begin{array}{l}26(25) \\
\text { Control participants }\end{array}$ \\
0 & 0 & $11(9)$ & $4(4)$ & $3(3)$ \\
\hline
\end{tabular}

The number of occurrences between brackets represents the number of times the change led to equivalent or more regular realizations.
Even though the discussion of the change processes remains descriptive, Table 8 shows that most of the changes indeed led to more regular stress patterns.

Summing up, the non-word repetition results have confirmed the hypothesis that Dutch aphasic patients have more difficulty repeating non-words with (highly) irregular and prohibited stress patterns than a nonbrain-damaged control group. Given their lower proportion of identical realizations, there is more room for regularization of irregular stress patterns for the aphasic population than for the control group. The results in Table 8 show that stress shift and weight loss were frequently applied to regularize the target. This indicates that aphasic patients rely on syllable structure when they produce non-identical realizations of (highly) irregular and prohibited target structures.

\section{Discussion}

In this study, we investigated stress assignment in reading aloud real and non-words and in repetition of nonwords in two groups of participants: aphasic patients and non-brain-damaged control participants. Whereas reading out real words produced analyzable results for the aphasic group, reading out non-words, particularly longer nonwords, turned out to be extremely problematic. When asked to read out trisyllabic words, aphasic patients came up with only 23/42 trisyllabic responses. Interestingly, word length did not pose difficulty for the aphasic patients in the non-word repetition task. Even the four-syllable words were realized as four-syllable items in almost $80 \%$ of the cases. This suggests that speech production from written input is much more problematic for these patients than speech production in repetition (cf. Nickels \& Howard, 1999). Nevertheless, the available results from the non-word reading task endorse findings of previous studies that have shown a preference for regular stress assignment of non-words in aphasic subjects (e.g. Galante et al., 2000, Janssen, 2003, Laganaro et al., 2002), as well as control subjects (Nouveau, 1994). The findings thus matched the expectation that both the aphasic and control groups assign regular stress to non-words. 
However, more solid evidence for highly irregular stress patterns being problematic to aphasic patients stems from the real-word reading data and the non-word repetition data. In reading, there was a tendency towards (relatively) more frequent regularization of irregular real words in the aphasic than in the control group. Whereas this effect may have been confounded with word frequency in the reading task (the items with the most irregular stress patterns may have been of lower frequency than the items with the more regular stress patterns which also affects ease of production), it was also found in the non-word repetition study, in which stored patterns did not confound the results. This sub-study then most clearly showed that aphasic patients had more difficulty with irregular stress patterns than the control group. Targets with irregular and prohibited stress patterns were regularized more often by the aphasic patients than by the non-brain-damaged control group, again in line with our expectations.

The results suggest that retention and retrieval of irregular stress patterns is difficult for the patients. Computation of stress on the basis of the regularities of Dutch, however, is unimpaired. Non-word repetition has not been used as a tool to investigate stress production in patients with aphasia before. The present study does not allow the claim that the present findings are generalizable to aphasic patients in general. The patient group was relatively small and heterogeneous. However, the current findings, are in line with earlier reading, naming, and speech data of Italian and German aphasic patients (Cappa et al., 1997; Galante et al., 2000; Janssen, 2003; Laganaro et al., 2002; Miceli \& Caramazza, 1993) which have shown that stress production of the patients relies on the stress regularities of the language. Our study has shown that in both reading and repetition, syllable structure and word length information are used as a cue for stress assignment by the aphasic patients tested in this experiment.

This brings us to the question why aphasic participants should have more difficulty than non-brain-damaged participants repeating (highly) irregular stress patterns than regular stress patterns. Repetition involves correct perception of lexical stress, maintaining the presented target stimulus in verbal short-term memory, phonological encoding, and actual production of the target.

Performance of the aphasic participants could be attributed to impaired stress perception. Aphasic patients' have been shown to be impaired in making lexical stress judgments, even when all the acoustic cues to stress were present (Baum, 1998). When asked to match an auditorily presented realization of hot dog to either a picture of a dog or to a snack, aphasic patients did not perform better than chance level. However, in an auditory lexical decision task in which polysyllabic words were either presented with a correct or an incorrect stress pattern, aphasic patients, similar to non-brain-damaged control participants, showed more errors (error here means that a misstressed word was given a NO response) and longer response times to misstressed words than to words with a correct stress pattern (Baum, 2002). Thus, the patients did not accept words with incorrect stress patterns. Since we did not include any comprehension tasks that hinge crucially on stress-appreciation, we cannot rule out the possibility that the aphasic patients under study had impaired stress perception.

An alternative interpretation is that a verbal short-term memory deficit is a main cause of the stress difficulties of the aphasic patients. Such an interpretation is endorsed by findings that short-term memory is involved in stress assignment in non-brain damaged participants. Dupoux, Pallier, Sebastian, and Mehler (1997) reported a memory overload on performance in a study on stress 'deafness' in French non-brain-damaged participants. Spanish, but not French uses lexical stress to distinguish between minimal stress pairs of words (e.g. tópo vs topó). Dupoux et al. found that French subjects had significantly more difficulties than Spanish subjects on word stress classification through an ABX task. In an additional experiment, using the simpler test paradigm of discrimination, however, Dupoux et al. found that the French subjects could respond to the acoustic correlates of lexical stress. This indicates that the initial stress problems of the French subjects should not be attributed to their perceptual capacities, but rather seem to be located in short-term memory. Stress distinctions that are not meaningful and thus not represented in the French language are more difficult to retain in memory for the French subjects than for the Spanish subjects, in particular in more taxing experimental settings. These findings underscore the role of short-term memory in stress abilities.

With respect to the aphasic patients, poor verbal short-term memory was attested in the present population. The patients had relatively spared auditory comprehension, but impaired performance on the Token test (see Table 1). Furthermore, there was a moderately strong correlation between patients' performance (in terms of identical score) in the non-word repetition task and their Token Test performance (Pearson's correlation, $R=0.66$ ).

The importance of poorer verbal short-term memory can be related to Hickok and Poeppel's $(2000,2004)$ proposal of a dorsal speech processing stream mapping sound onto articulatory-based representations. This stream represents a tight connection between speech perception and speech production and provides the basis for verbal short-term memory (Baddeley, 1992). Broca's area activation has been reported in verbal working memory tasks (Awh et al., 1996), and in perception tasks requiring articulatory recoding (Burton, Small, \& Blumstein, 2000). Thus, under the assumption that a broad fronto-parietal network underlies verbal short-term memory performance, affected verbal short-term memory seems the most likely underlying cause for the difficulties of the aphasic patients under study.

This interpretation is also in line with expectations based on neural network models. In these models, a 
verbal short-term memory component interacts with longterm phonological knowledge. If the integrity of representations and/or transmission of activation between levels is reduced, low frequent patterns with weak connections stand a small chance of survival in, for example, nonword repetition. Thus, if fast access to low-frequent representations is hampered (in reading) or if the representation in verbal short-term memory decays quickly (in non-word repetition), stress has to be assigned on the basis of the most frequent patterns in the language. Long-term phonological knowledge (in terms of grapheme-to-phoneme conversion and syllable structure knowledge) is thus translated into connection weights. This resembles the output pattern of the aphasic patients. Their stress assignment in both non-word repetition as well as word and non-word reading showed similar patterns of difficulty.

The reading deficit in dyslexia has been argued to be caused by phonological processing difficulties (e.g. Ramus, 2003; Snowling, 2001), incorporating both poorer phonological-lexical knowledge and limited verbal short-term memory. This renders the expectation that stress production should also be poorer for a dyslexic population than for a non-dyslexic population. Indeed, it has been found that non-word repetition of these same targets was poorer in a group of children with a familial risk of dyslexia (de
Bree, Wijnen, \& Zonneveld, 2006) and a group of children with developmental dyslexia (de Bree, 2007) than in their age-matched controls. Thus, in both aphasia and dyslexia, production of irregular stress patterns is affected and yields regularization of irregular patterns. These findings agree with assumptions that the architecture of the cognitive system in both dyslexia and aphasia is affected similarly (see Jackson \& Coltheart, 2001) and can be couched in a connectionist perspective of language and reading in both disorders.

A question remains whether it is impaired stress perception, the phonological (temporary) storage or the conversion from the temporary auditory representation to a speech motor pattern for production that is affected, and yields impaired stress production in patients with aphasia. Future research could further investigate the contributions of these separate components to establish what mainly underlies these stress difficulties.

\section{Acknowledgments}

We extend our gratitude to the participants of this study, to Mia Verschaeve and Janneke Wolters-Westerhout (Afasiecentrum Rotterdam en Omstreken) for introducing us to the aphasic participants, and to Eline Westerhout for assisting in data collection.

Appendix A

Visual presentation of regular stress assignment in Dutch monomorphemic words, based on syllable structure

\begin{tabular}{|c|c|c|c|c|c|c|}
\hline & py & $\begin{array}{l}\text { * } \\
\text { pás } \\
\text { já }\end{array}$ & $\begin{array}{l}\text { ta } \\
\mathrm{ma}\end{array}$ & & & \\
\hline \multirow[t]{3}{*}{ Syllables } & any & any & light & & & \\
\hline & & * & & * & & \\
\hline & $\mathrm{e}$ & lék & tron & á & na & nas \\
\hline \multirow[t]{4}{*}{ Syllables } & any & heavy & heavy & any & light & heavy \\
\hline & & & * & & & * \\
\hline & & stu & dent & $\mathrm{a}$ & ve & ríj \\
\hline & te & le & fóón & & kar & wéi \\
\hline Syllables & any & any & superheavy & any & any & diphthong \\
\hline
\end{tabular}

\section{Appendix B}

Stimuli of the real-word reading task, divided by weight, number of syllables, and stress regularity

\begin{tabular}{|c|c|c|c|c|}
\hline Final syllable weight & No. of syllables & Regular stress & Irregular stress & Highly irregular stress \\
\hline \multicolumn{5}{|l|}{ Regularity } \\
\hline \multirow[t]{4}{*}{ Light } & 2 & pásta [pasta] & & kadó [present] \\
\hline & 3 & bikíni [bikini] & Eskimo [Eskimo] & paraplú [umbrella] \\
\hline & 3 & agénda [diary] & & frikandó [fricandeau] \\
\hline & 4 & televísie [television] & Amérika [America] & cavaleríe [cavalry] \\
\hline
\end{tabular}


Appendix B (continued)

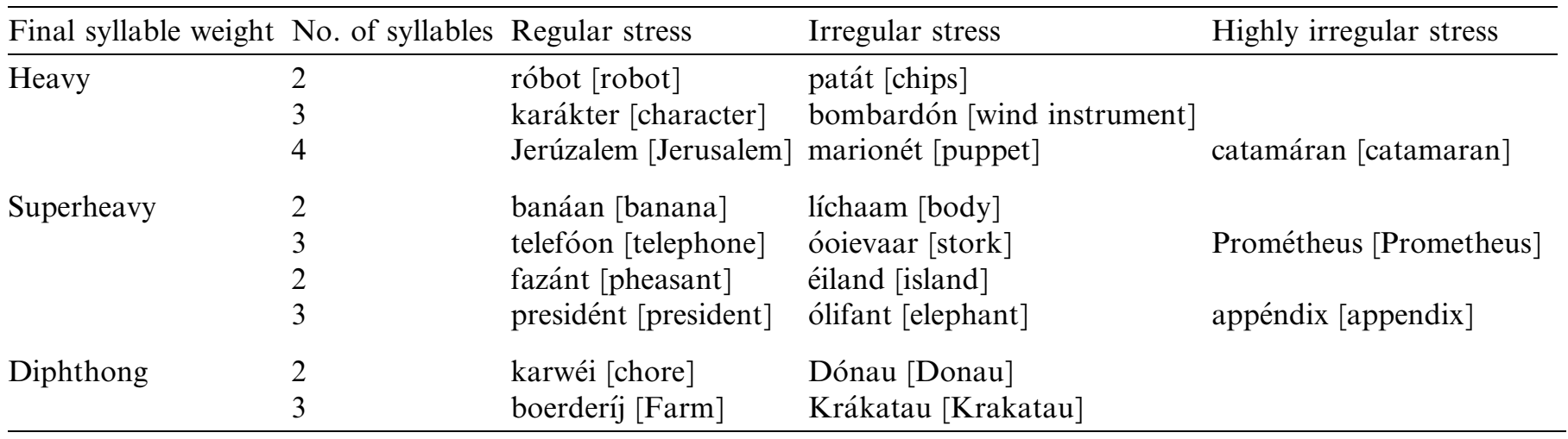

\section{Appendix C}

Stimuli of the non-word reading task, divided by weight and number of syllables

\begin{tabular}{lll}
\hline Final syllable weight & No. of syllables & Stimulus \\
\hline Light & 2 & bola \\
& 3 & fenimo \\
& 3 & kanakta \\
& 4 & karabilo \\
Heavy & 2 & kakot \\
& 3 & dapikon \\
& 3 & talaktan \\
Superheavy & 4 & monitaron \\
& 2 & bokaat \\
& 3 & karimoon \\
Diphthong & 2 & kadont \\
& 3 & falidont \\
& 2 & katei \\
\hline
\end{tabular}

\section{Appendix D}

Stimuli of the non-word repetition task, divided by weight, number of syllables, and stress regularity

\begin{tabular}{|c|c|c|c|c|c|}
\hline Final syllable weight & No. of syllables & Regular stress & Irregular stress & Highly irregular stress & Prohibited stress \\
\hline \multicolumn{6}{|l|}{ Regularity } \\
\hline \multirow[t]{4}{*}{ Light } & 2 & bóla & & sotá & \\
\hline & 3 & fenímo & kémito & genimó & \\
\hline & 3 & kanákta & & tamaktá & págakta \\
\hline & 4 & karabílo & taládilo & pawatiló & bálapulo \\
\hline \multirow[t]{4}{*}{ Heavy } & 2 & kákot & watóp & & \\
\hline & 3 & dápikon & katipón & pakídon & \\
\hline & 3 & taláktan & kawaptán & & pánaktam \\
\hline & 4 & monítaron & notimalón & tonimáron & nómipalon \\
\hline \multirow[t]{4}{*}{ Superheavy } & 2 & bokáat & kóbaat & & \\
\hline & 3 & karimóon & tánidoom & palíkoon & \\
\hline & 2 & kadónt & tágont & & \\
\hline & 3 & falidónt & sánitont & parígont & \\
\hline \multirow[t]{2}{*}{ Diphthong } & 2 & katéi & tánei & & \\
\hline & 3 & dotiféi & kópitei & pokídei & \\
\hline
\end{tabular}




\section{References}

Awh, E., Jonides, J., Smith, E. E., Schumacher, E. H., Koeppe, R. A., \& Katz, S. (1996). Dissociation of storage and rehearsal in working memory: PET evidence. Psychological Science, 7, 25-31.

Baddeley, A. D. (1992). Working memory. Science, 255, 556-559.

Baum, S. R. (1998). The role of fundamental frequency and duration in the perception of linguistic stress by individuals with brain damage. Journal of Speech, Language, and Hearing Research, 41, 31-40.

Baum, S. R. (2002). Word recognition in individuals with left and right hemisphere damage: the role of lexical stress. Applied Psycholinguistics, 23, 233-246.

Burton, M. W., Small, S. L., \& Blumstein, S. E. (2000). The role of segmentation in phonological processing: An fMRI investigation. Journal of Cognitive Neuroscience, 12(4), 679-690.

Butterworth, B. (1992). Disorders of phonological encoding. Cognition, $42,261-286$.

Cappa, S. F., Nespor, M., Ielasi, W., \& Miozzo, A. (1997). The representation of stress: Evidence from an aphasic patient. Cognition, 65, 1-13.

Daelemans, W., Gillis, S., \& Durieux, G. (1994). The acquisition of stress: A data-oriented approach. Computational Linguistics, 20, 421-451.

de Bree, E., Wijnen, F., \& Zonneveld, W. (2006). Word stress production in three-year-old children at risk for dyslexia. Journal of Research in Reading, 29, 304-317.

de Bree, E. (2007). Dyslexia and phonology: A study of the phonological abilities of Dutch children at-risk of dyslexia. Dissertation Utrecht University, LOT series 155 .

Dell, G. S., Schwartz, M. F., Martin, N., Saffran, E. M., \& Gagnon, D. A. (1997). Lexical access in aphasic and non-aphasic speakers. Psychological Review, 104, 801-838.

Den Ouden, D. B. (2002). Phonology in aphasia: Syllables and segments in level-specific deficits. Dissertation Groningen University, GRODIL (Groningen dissertations in Linguistics). Enschede, The Netherlands: Print Partners.

Dupoux, E., Pallier, C., Sebastian, N., \& Mehler, J. (1997). A destressing 'deafness' in French? Journal of Memory and Language, 36, 406-421.

Galante, E., Tralli, A., Zuffi, M., \& Avanzi, S. (2000). Primary progressive aphasia: A patient with stress assignment impairment in reading aloud. Neurological Science, 21, 39-48.

Gathercole, S., \& Martin, A. (1996). Interactive processes in phonological memory. In S. E. Gathercole (Ed.), Models of working memory (pp. 149-178). Hove, UK: Psychology Press.

Gillis, S., Daelemans, W., \& Durieux, G. (2000). 'Lazy learning': A comparison of natural and machine learning of word stress. In P. Broeder \& J. Murre (Eds.), Models of language acquisition (pp. 76-99). Oxford: Oxford University Press.

Graetz, P., de Bleser, R., \& Willmes, K. (1992). Akense Afasietest (AAT) Lisse. The Netherlands: Swets and Zeitlinger.

Gupta, P., \& MacWhinney, B. (1997). Vocabulary acquisition and verbal short-term memory: Computational and neural bases. Brain and Language, 59, 233-267.

Hickok, G., \& Poeppel, D. (2000). Towards a functional neuroanatomy of speech perception. Trends in Cognitive Sciences, 4, 131-138.
Hickok, G., \& Poeppel, D. (2004). Dorsal and ventral streams: A framework for understanding aspects of the functional anatomy of language. Cognition, 92, 67-99.

Jackson, N. E., \& Coltheart, M. (2001). Routes to reading success and failure. Hove, UK: Psychology Press.

Janssen, U. (2003). Stress assignment in German patients with surface dyslexia. Brain and Language, 87, 114-115.

Joanisse, M., \& Curtin, S. (1999). Dutch stress acquisition: OT and connectionist approaches. Proceedings of SWOT 5. San Diego: University of California.

Kager, R. (1989). A Metrical theory of stress and destressing in English and Dutch [Linguistic Models, 14.]. Dordrecht: Foris Publications.

Laganaro, M., Vacheresse, F., \& Frauenfelder, U. H. (2002). Selective impairment of lexical stress assignment in an Italian-speaking aphasic patient. Brain and Language, 81, 601-609.

Miceli, G., \& Caramazza, A. (1993). The assignment of word stress in oral reading: Evidence from a case of acquired dyslexia. Cognitive Neuropsychology, 10, 273-296.

Nickels, L., \& Howard, D. (1999). Effects of lexical stress on aphasic word production. Clinical Linguistics \& Phonetics, 13, 269-294.

Nouveau, D. (1994). Language acquisition, metrical theory, and optimality. Utrecht: OTS Dissertation Series.

Plaut, D. C., McClelland, J. L., Seidenberg, M. S., \& Patterson, K. (1996). Understanding normal and impaired word reading: Computational principles in quasi-regular domains. Psychological Review, 103, 56-115.

Ramus, F. (2003). Developmental dyslexia: Specific phonological deficit or general sensorimotor dysfunction? Current Opinion in Neurobiology, $13,212-218$.

Romani, C., \& Galuzzi, C. (2005). Effects of syllabic complexity in predicting accuracy of repetition and direction of errors in patients with articulatory and phonological difficulties. Cognitive Neuropsychology, 22(7), 817-850.

Seidenberg, M. S. (1997). Language acquisition and use: Learning and applying probabilistic constraints. Science, 275, 1599-1603.

Sluijter, A. M. (1995). Phonetic correlates of stress and accent. Doctoral dissertation Leiden University, The Hague: Holland Academic Graphics.

Snowling, M. J. (2001). From language to reading to dyslexia. Dyslexia, 7 , $37-46$.

Southwood, M. H., \& Chatterjee, A. (2001). The Simultaneous Activation Hypothesis: Explaining recovery from deep to phonological dyslexia. Brain and Language, 76, 18-34.

Trommelen, M. (1991). Dutch word stress: Extrametricality and feet. In: T. F. Shannon, \& J. P. Snapper (Eds). The Berkeley Conference on Dutch Linguistics 1989: Issues and Controversies, Old and New (pp. 157-173), Lanham: University Press of America.

Trommelen, M., \& Zonneveld, W. (1989). Klemtoon en metrische fonologie. Muiderberg: Coutinho.

Trommelen, M., \& Zonneveld, W. (1999). Word-stress in WestGermanic: English and Dutch. In H. v. d. Hulst (Ed.), Word prosodic systems in the languages of Europe (pp. 477-514). Berlin: Mouton de Gruyter. 